\title{
Effect of Heat Input to Mechanical properties of Joint for 16MnR and S31803
}

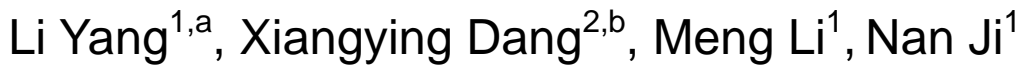 \\ ${ }^{1}$ School of Mechanical and Electronic Engineering, Xuzhou Institute of Technology, Xuzhou, China \\ 221008 \\ ${ }^{2}$ School of Information and Electronic Engineering, Xuzhou Institute of Technology, Xuzhou, China \\ 221008 \\ alinlideyu@126.com, bdangpaper@163.com
}

Keywords: Dissimilar metal, Duplex stainless steel, Heat input, Mechanical properties

\begin{abstract}
The dissimilar joints of $16 \mathrm{MnR}$ and S31803 were obtained by means of SMAW and GTAW. Hardness of joints has been tested. The results show that hardness distribution from 16MnR base metal to S31803 base metal presents upward trend. Hardness of seam welded by GTAW is higher than seam welded by SMAW. The peak value of hardness appeared in S31803 base metal near fusion line. Peak width of joint welded by SMAW is larger than that of GTAW. The hardness in carbon migration area undergoes a wave process that decrease first, then increase, decrease finally, accompanied by the change of micro-area from base metal to decarburized layer to carbon-enriched layer to welding metal. The fluctuation degree is proportional to heat input.
\end{abstract}

\section{Introduction}

S31803 duplex stainless steel contains 22\% Cr and is usually obtained by solution treatment. In normal the microstructure of S31803 is 50\% austenite and 50\% ferrite. So S31803 steel has higher yield strength and good plasticity, and also has good low-temperature impact performance, excellent resistance to stress corrosion, intergranular corrosion, point corrosion and crevice corrosion resistance. Those properties make it preferably apply in certain environments such as chemical tankers, paper making and ocean engineering ${ }^{[1,2]}$.

Hardness test is a simple method in mechanical performance tests. In the paper the mechanical property of $16 \mathrm{MnR}$ and S31803 weld joint is studied, the relationship between mechanical property and microstructure is discussed and the influence of heat input to mechanical property is revealed, which provide a direction for practice.

\section{Experiments}

Test Materials. The chemical composition of testing material 16MnR and S31803 is shown in Table 1 . The base metals of $16 \mathrm{MnR}$ are machined to the dimension of $130 \mathrm{~mm} \times 100 \mathrm{~mm} \times 10 \mathrm{~mm}$ and the S31803 are $30 \mathrm{~mm} \times 80 \mathrm{~mm} \times 10 \mathrm{~mm}$.

Table 1 The chemical composition of testing materials [\%]

\begin{tabular}{|c|c|c|c|c|c|c|c|c|c|}
\hline Num. & $\mathrm{C}$ & $\mathrm{Si}$ & $\mathrm{Mn}$ & $\mathrm{Ni}$ & $\mathrm{Cr}$ & $\mathrm{N}$ & $\mathrm{S}$ & $\mathrm{P}$ & Mo \\
\hline S31803 & 0.025 & 0.570 & 1.250 & 5.300 & 22.570 & 0.140 & 0.002 & 0.030 & 3.000 \\
\hline 16MnR & 0.160 & 0.360 & 1.470 & & & & 0.003 & 0.027 & \\
\hline E2209-16 & 0.028 & 0.600 & 1.670 & 9.130 & 22.840 & 0.11 & 0.011 & 0.025 & 3.150 \\
\hline ER2209 & 0.026 & 0.700 & 1.300 & 8.920 & 22.770 & 0.130 & 0.010 & 0.020 & 3.040 \\
\hline
\end{tabular}

Welding Parameters. Preparation before Welding: Before welding, both sides of the welding groove in $30 \mathrm{~mm}$ are strictly cleaned, free from grease and rust. The assembly method and groove is shown is Fig.1. 


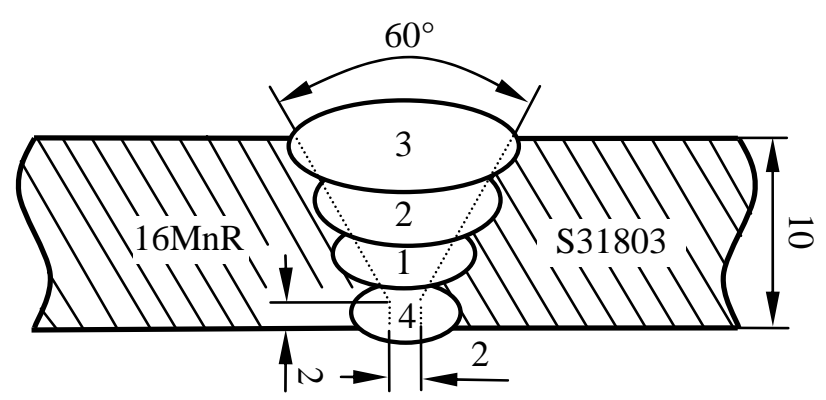

Fig. 1 The schematic diagram of welded joint

Welding Points and Welding Parameters: The layer temperature is strictly controlled below $120^{\circ} \mathrm{C}$.Ferrite measurement is done after the each layer weld. To lower the precipitation of intermetallic phase and the dilution of $16 \mathrm{MnR}$ to weld metal, multi-layer welding and multi-pass welding is adopted to reduce the holding time in high temperature area. The welding parameters are shown in Table 2.

Table 2 Welding procedure parameters

\begin{tabular}{|c|c|c|c|c|c|}
\hline \multirow{2}{*}{$\begin{array}{l}\text { Welding } \\
\text { Process }\end{array}$} & \multicolumn{2}{|c|}{ Welding current } & \multirow{2}{*}{\begin{tabular}{|l} 
Arc \\
Voltage[V]
\end{tabular}} & \multirow{2}{*}{$\begin{array}{l}\text { Welding Speed } \\
\text { [mm/min] }\end{array}$} & \multirow{2}{*}{ Airflow $[\mathrm{L} / \mathrm{min}]$} \\
\hline & Polarity & Current[A] & & & \\
\hline SMAW & DCRP & 110-135 & $24-25$ & $800-120$ & \\
\hline GTAW & DCSP & 90-130 & $11-15$ & $50-80$ & Ar10 15 \\
\hline
\end{tabular}

Metallographic Observation. The standard method of metallographic sample preparation is adopted, and the section perpendicular to the welding direction is taken as object . The samples are grinded and polished and then etched by $4 \%$ nitric acid alcohol solution to observe the structure of $16 \mathrm{MnR}$ side. Polish the samples once more and etch with $40 \% \mathrm{NaOH}$ solution to proceed electrolytic corrosion. The electrolysis is lasted for a long time to watch the microstructure in S31803 steel side and weld seam.

Hardness Test. Because of the tiny indentation of microhardness test, the samples' surface roughness will affect the test results directly. So the samples' hardness should be tested as soon as pass through polishing and etching. Microhardness tester (TMVS-1S) is used for determine microhardness at joints' different area and loaded with $200 \mathrm{~g}$ for $15 \mathrm{~s}$ during testing.

\section{Results and Analysis}

Effect of Heat Input on Interface (16MnR/WM) Hardness. The hardness at 16MnR side is shown in Fig.2. It can be seen that hardness distribution from 16MnR base metal to weld seam presents upward trend. The hardness in seam is higher than that in $16 \mathrm{MnR}$ base metal apparently. Hardness of seam welded by GTAW is higher than seam welded by SMAW. The structure of weld seam is shown in Fig.3 and the structure in a is welded by GTAW, in b is by SMAW. Strip-shaped austenite and acicular ferrite is observed in weld seam and in which the austenite content is at dominant level. Austenite content in SMAW beam is higher than that of GTAW seam.

The solidification mode of welding material 2209 is the mode called ferrite solidification mode. That is to say, the structure is ferrite at higher temperature and will transform into austenite with the decrease of temperature. The longer holding time of SMAW beam in high temperature area promotes the transformation of ferrite to austenite ${ }^{[3]}$. And the solid solution of large amounts alloy elements in ferrite makes the bigger hardness ${ }^{[4]}$. So the hardness of seam welded by GTAW is higher than that of SMAW. 


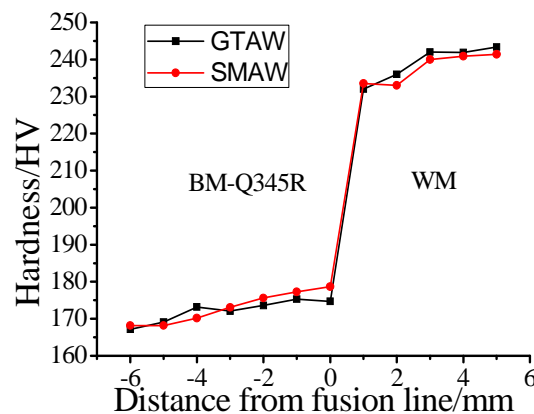

Fig. 2 Microhardness distribution curves
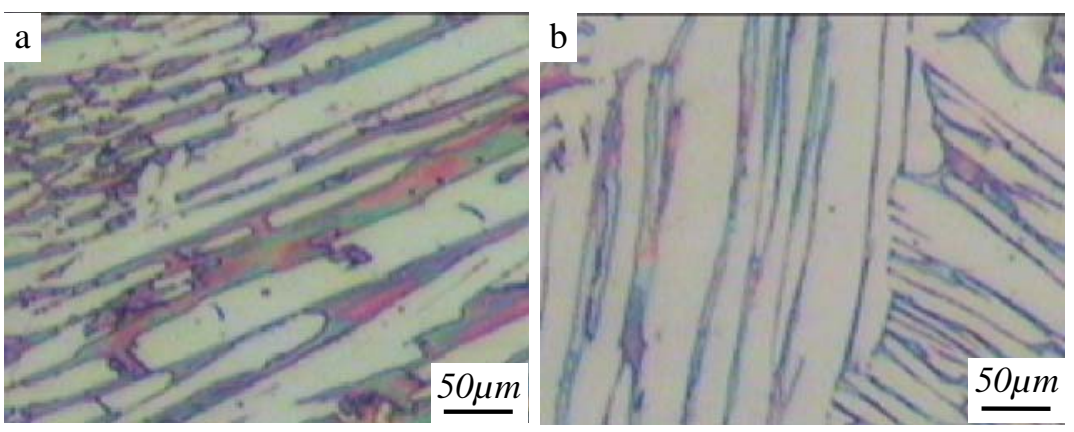

Fig. 3 Microstructure of seams

Effect of heat input on interface (WM/ S31803) hardness. Microhardness distribution at interface between seam and S31803 is shown in Fig.4. It shows an overall upward trend from seam to S31803 base metal and the peak value of hardness appears in S31803 base metal near fusion line. Peak width of joint welded by SMAW is larger than that of GTAW.

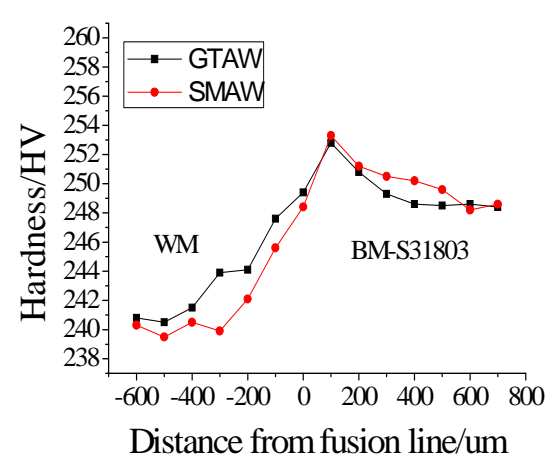

Fig. 4 Microhardness distribution

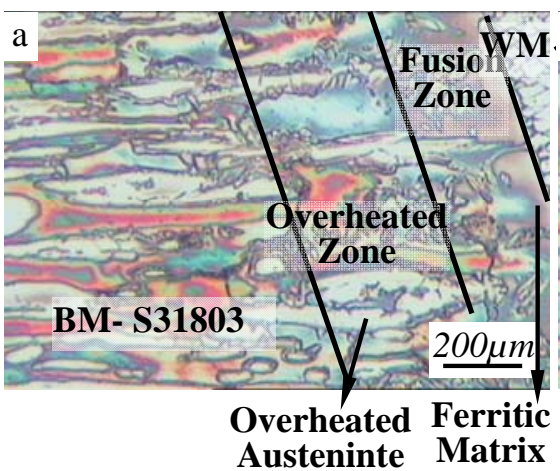

Fig. 5 Microstructure on the side of S31803

Microstructure of joint on the side of S31803 is shown in Fig.5. They are structure of GTAW joint on the side of S31803 in figure a and SMAW joint on the side of S31803 in figure b. From left to right in turn is S31803 base metal, overheated zone, fusion zone and weld seam. Comparing the figure $a$ and $b$, it can be seen that the fusion zone on the side of S31803 of GTAW joint is clearly wider than that of GTAW joint. Under high temperature of welding arc, a part of base metal on S31803 side is fusing, at the same time ,the rapid cooling of weld process makes it is difficult for the ferrite transformation to austenite, so the increased ferrite in fusion zone leads to the increase of hardness. The bigger heat input of SMAW makes more base metal to fuse, and so there is a wider fusion zone and peak width.

Effect of Heat input on hardness of carbon migration micro-region. Indentations of hardness test in carbon migration micro-region are shown in Fig.6. They respectively are the indentations of the second layer of carbon-enriched layer (a), the first layer of decarburized layer (b) and the third layer of decarburized layer (c). Microhardness distribution in carbon migration micro-region at 16MnR side on 1,2,3 layer respectively is shown in Fig.7. Hardness experiences the fluctuation of decrease, and then rise from $16 \mathrm{MnR}$ base metal to weld seam. The first layer has the biggest fluctuation range and follows by the second layer and the third layer.

The using of multi-layer welding makes the temperature of previous layer increase when the next layer is welded. The bigger the carbon migration rate, the bigger the carbon migration extent. The first layer has the longest holding time, so there is much more carbon migration and serious decarburization. The biggest hardness and the smallest hardness respectively appear in decarburized layer and carbon-enriched layer. The fluctuation degree matches the holding time in high temperature zone, that is, proportional to heat input 


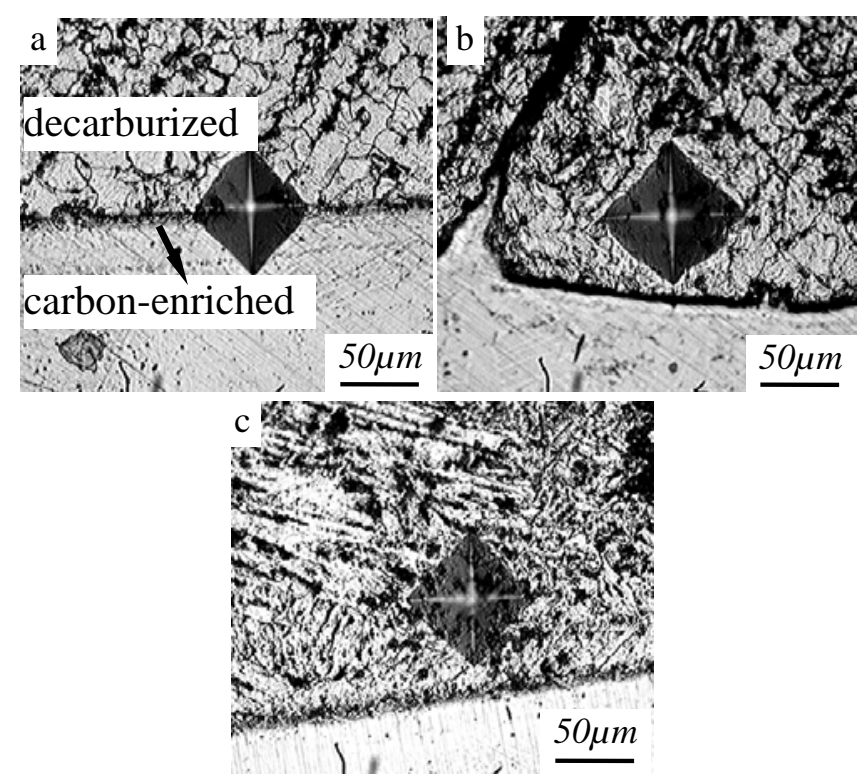

Fig. 6 Hardness indentation

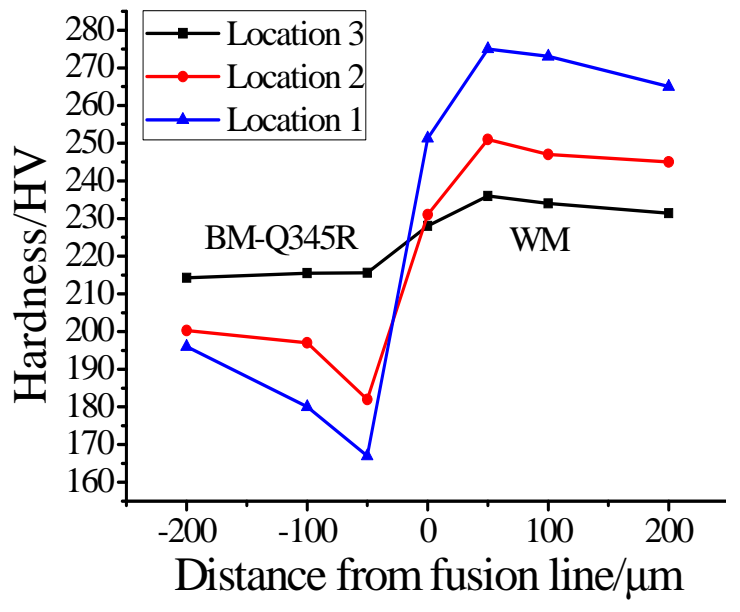

Fig. 7 Microhardness distribution curves

\section{Conclusions}

1) The hardness distribution from $16 \mathrm{MnR}$ base metal to weld seam presents upward trend, and the hardness in seam is higher than that of $16 \mathrm{MnR}$ base metal clearly. Because of the influcence of heat input, hardness of seam welded by GTAW is higher than seam welded by SMAW.

2) From weld seam to $16 \mathrm{MnR}$ base metal the hardness shows an upward trend overall, and the base metal has higher hardness. Because of the rapid cooling of weld process, in base metal the formation of ferrite leads to the hardness increase, and so the peak value appeares in S31803 base metal near fusion line. .

3) Using multi-layer welding, heat effect of the next layer's welding leads to the longer holding time of previous layer in high temperature zone. Different hardness variations are observed in different layers at the same weld beam, and present a down and up trend basicaly. The fluctuation degree is proportional to heat input.

\section{Acknowledgements}

The authors acknowledge the financial support of this work from the Scientific and Technology Support Program of Jiangsu Province (BE2011048).

\section{References}

[1] Z.C. Han, S.G. Wang. Corrosion \& Protection in Petrochemical Industry, Vol. 3 (2008) No.4, p.1.

[2] L. Yang, C. Wang. Hot Working Technology, Vol.17 (2010) No.39, p.158.

[3] B. Riad, B. Mabrouk, B. Brigitte. Materials Characterization, Vol. 59 (2008) p.447.

[4] Q.H. Ma: Research on welding technology of duplex stainless steel and dissimilar metals and joint microstructure and properties (MS., Nanjing University Of Aeronautics And Astronautics, China 2010), p.67. 